\title{
THE INFLUENCE OF CONCORDANT XENOGRAFTS ON THE HUMORAL AND CELL-MEDIATED IMMUNE RESPONSES TO SUBSEQUENT ALLOGRAFTS IN PRIMATES
}

Robert E. Michler, MD ${ }^{a}$

Aamir S. Shah, MD ${ }^{a}$

Silviu Itescu, MD ${ }^{\mathrm{a}}$

Daniel P. O'Hair, $\mathrm{MD}^{\mathrm{a}}$

Sorina Tugulea, $\mathrm{MD}^{\mathrm{b}}$

Pawel A. Kwiatkowski, MD

Z. Liu, $\mathrm{PhD}^{\mathrm{b}}$

Jeffrey L. Platt, $\mathrm{MD}^{\mathrm{c}}$

Eric A. Rose, $\mathrm{MD}^{\mathrm{a}}$

Nicole Suciu-Foca, $\mathrm{PhD}^{\mathrm{b}}$
The humoral and cell-mediated immune responses to subsequent allografts were determined in primate recipients after concordant xenotransplantation as a bridge to allotransplantation. Heterotopic heart transplants $(n=$ 4) were performed from cynomolgus monkeys into $\mathrm{ABH}$ type-matched olive baboons followed 2 weeks later by allotransplantation from $\mathrm{ABH}$ typematched baboon donors. Allografts were explanted at 8 weeks. All recipients underwent splenectomy at the time of xenotransplantation and received immunosuppression with cyclosporine, azathioprine, and methylprednisolone. Concordant xenotransplantation in these primates did not induce humoral or cell-mediated immune responses that jeopardized subsequent allografts. The degree of xenospecific immune reactivity, as determined by specific cytotoxicity of recipient $\mathbf{T}$-cell lines derived from the xenograft and extent of histologic xenograft rejection, did not predict the severity of subsequent allograft rejection. In two of the four recipients, xenotransplantation induced an alloreactive humoral response against antigens expressed by the $B$ cells of more than $50 \%$ of members from a panel of 12 unrelated baboons. In all recipients, priming with xenogeneic splenocytes in vitro induced an accelerated proliferative $T$-cell response to allogeneic lymphocytes from $16 \%$ of this panel. This study affirms the role of concordant xenografts as appropriate biologic bridges to human allotransplantation. However, our results suggest that xenoreactive baboon memory CD4 T cells may recognize major histocompatibility complex class II-like structures shared between the xenogeneic and allogeneic targets. The potential allorecognition induced by a xenograft may affect the process of subsequent allograft donor selection. (J Thorac Cardiovasc Surg 1996;112:1002-9)
A though clinical heart transplantation with human cadaveric donors is recognized as the most effective therapy for patients with end-stage heart disease, the supply of human donor hearts remains

From the Cardiac Transplantation Research Laboratory, Departments of Surgery ${ }^{\mathrm{a}}$ and Pathology, ${ }^{\mathrm{b}}$ Columbia-Presbyterian Medical Center, New York, N.Y., and Department of Surgery, ${ }^{c}$ Duke University Medical Center, Durham, N.C.

Supported in part by National Institutes of Health grant PPG PO1HL36581-01A1.

Received for publication June 26, 1995; revisions requested Nov. 29, 1995; revisions received Dec. 22, 1995; accepted for publication Jan. 9, 1996.

Address for reprints: Robert E. Michler, MD, Director, Cardiac Transplant Service, Director, Cardiac Transplant Research Laboratory, Columbia-Presbyterian Medical Center, Milstein Hospital Building, 7-435, 177 Fort Washington Ave, New York, NY 10032.

Copyright (c) 1996 by Mosby-Year Book, Inc.

$0022-5223 / 96 \$ 5.00+0 \quad \mathbf{1 2} / \mathbf{1 / 7 1 7 2 2}$ inadequate to meet the ever-increasing demand. ${ }^{1-3}$ The experimental search for an alternative to human heart transplantation has focused primarily on two alternatives: mechanical devices and cross-species transplants (xenografts). For children and adults with a total body surface area less than $1.5 \mathrm{~m}^{2}$, in whom mechanical devices are not applicable, xenografts may be the preferred alternative. ${ }^{4}$

The field of clinical cross-species transplantation was pioneered by Reemtsma and colleagues 5 in 1963. Reemtsma transplanted chimpanzee kidneys into human beings and achieved functional graft survival for up to 9 months with the use of azathioprine and steroid based immunosuppression. Although initial attempts at clinical heart xenotransplantation were largely unsuccessful, experimental studies during the past decade have demonstrated the feasibility and potential benefit of cross-species heart transplantation. ${ }^{9-12}$

Although much excitement has been generated by 
the development of transgenic pigs, it is unlikely that these animals will be ready for clinical trials within the next 5 years. Moreover, colony-bred baboons may be available in sufficient numbers to meet the pediatric demand for hearts. ${ }^{13}$

Rejection of a concordant xenograft is characterized histologically by mononuclear and polymorphonuclear cellular infiltrates accompanied by interstitial edema and eventually hemorrhage, vascular thrombosis, and myocyte necrosis. ${ }^{10}$ These features result from immunologic effector mechanisms involving both humoral and cellular responses to concordant xenografts. ${ }^{9,14-19}$ These findings raise the question of whether a concordant xenograft implanted as a temporary bridge to allotransplantation could induce a humoral or cell-mediated immune response that is capable of jeopardizing a subsequent allograft. The issue of sensitization to subsequent allografts induced by concordant xenotransplantation has been investigated in rodent and canine animal models but has not been well studied in primates. ${ }^{20-23}$ Findings in smaller animal models have been equivocal. In a hamster-to-rat heterotopic heart transplant model, there was no difference in untreated allograft survival after xenotransplantation. ${ }^{21}$ In contrast, survival of canine allografts in a wolf-to-dog heterotopic heart transplant model was found to be decreased after concordant xenotransplantation, with five of nine allografts undergoing "hyperacute" rejection within 48 hours of implantation. ${ }^{20}$ The mechanism of the rejection response was presumed to be humoral, this presumption being based primarily on histopathologic findings. The antibody response of the recipients to their xenografts was monitored only by hemagglutination of xenograft donor erythrocytes, and this response did not correlate with allograft rejection. The applicability of data from small animal studies to the human condition is questionable inasmuch as the identity of relevant xenoantigens in these species have not been clearly established.

The purpose of this study, therefore, was to determine how a concordant primate xenograft influences the rejection of a subsequent allograft. A cynomolgus monkey-to-olive baboon heart transplant model was selected because the degree of immunologic disparity between these species is believed to closely parallel that between human beings and higher primates and may uniquely reflect rejection reactions expected between human beings and baboons. $^{24}$

\section{Materials and methods}

Animals. Concordant heterotopic heart xenotransplants were performed using cynomolgus monkey (Macaca fascicularis) donors into $\mathrm{ABH}$ type-matched olive baboons (Papio anubis; $n=4$ ). The xenografts were explanted after 2 weeks, followed by allotransplantation from ABH type-matched olive baboon donors. Allografts were explanted after 8 weeks. ABH compatibility was determined by salivary analysis. ${ }^{25,26}$

Surgical procedures and subsequent care of animals were performed in compliance with the Principles of Laboratory Animal Care formulated by the National Society for Medical Research and the "Guide for the Care and Use of Laboratory Animals" prepared by the National Academy of Sciences and published by the National Institutes of Health (NIH publication No. 85-23, revised 1985).

Heterotopic cervical heart transplantation. Donor heart procurement, graft preparation, and recipient cervical implantation were performed as previously described by Michler and associates. ${ }^{27}$ In brief, donor hearts were procured in a fashion similar to the manner in which human hearts are harvested for allotransplantation, with University of Wisconsin preservation solution $(15 \mathrm{ml} / \mathrm{kg}$, $4^{\circ} \mathrm{C}$, infusion pressure 50 to $100 \mathrm{~mm} \mathrm{Hg}$ ). The grafts were implanted into the baboon recipients in the cervical position by performing end-to-side anastomoses with continuous polypropylene suture first between the donor aorta and recipient carotid artery and second between the donor pulmonary artery and recipient jugular vein. All recipients underwent splenectomy at the time of xenotransplantation. The total number of animals undergoing this procedure was four and survival was $100 \%$.

Heterotopic allotransplantation in baboon recipients was performed in the contralateral side of the neck at the time of xenograft explantation. All recipients received cyclosporine $(15 \mathrm{mg} / \mathrm{kg}$ per day), azathioprine $(3 \mathrm{mg} / \mathrm{kg}$ per day), and methylprednisolone $(0.8 \mathrm{mg} / \mathrm{kg}$ per day) immunosuppression from the time of xenotransplantation. Biopsy specimens for light and immunofluorescence microscopy were obtained from the xenograft 1 and 2 weeks after transplantation and from the allograft 1,4 , and 8 weeks after transplantation. Rejection episodes were not treated.

Histology/immunopathology. Samples of graft tissue for immunohistochemical evaluation were snap frozen in prechilled isopentane and liquid nitrogen and stored at $-70^{\circ} \mathrm{C}$. As described previously, specimens were cut into $4 \mu \mathrm{m}$ sections in a cryostat (Leica Vertrieb $\mathrm{GmbH}$, Bensheim, Germany) at $-25^{\circ} \mathrm{C}$, air dried, fixed in acetone for 10 minutes, and washed with phosphatebuffered saline solution ( $\mathrm{pH}$ 7.4). ${ }^{28}$ Each section was then incubated with either an affinity-isolated, fluorescein isothiocyanate (FITC)-conjugated, labeled primary antibody or with an unlabeled murine monoclonal antibody (MAb). FITC goat antihuman immunoglobulins ( $\mathrm{Ig}$ ) $\mathrm{G}$ and $\mathrm{M}$ were obtained from Kirkegaard \& Perry Laboratories (Gaithersburg, Md.). FITC goat antihuman $\mathrm{C} 3$ was obtained from Cappel Laboratories (Organon Teknika Corp., Durham, N.C.). FITC goat 
antihuman $\mathrm{C} 4$ and FITC rabbit antihuman fibrin were obtained from Accurate Chemical \& Scientific Corp. (Westbury, N.Y.). A murine MAb against the membrane attack complex (MBM5) was generously provided by Alfred Michael (University of Minnesota, Minneapolis, Minn.). Mouse antihuman CD11/CD18 (OKM1) was obtained from Ortho Pharmaceutical Corporation (Raritan, N.J.), and mouse antihuman CD9 (BA-2) was the gift of T. W. LeBien (University of Minnesota). The unlabeled MAbs were detected with affinity-isolated FITC F(ab') ${ }_{2}$ goat antimouse IgG (Cappel) followed by affinity-isolated FITC $\mathrm{F}\left(\mathrm{ab}^{\prime}\right)_{2}$ rabbit antigoat IgG (Cappel). Before use, the secondary antibodies were $a b-$ sorbed with pig and human serum. Sections were washed with phosphate-buffered saline solution and mounted in a solution containing $p$-phenylenefiamine. ${ }^{29}$ In all experiments, control sections were stained as described herein; however, the primary antibodies were omitted.

Biopsy specimens from the grafts for histologic study were fixed in formalin, embedded in paraffin, sectioned, and stained with hematoxylin and eosin. Rejection was graded 0 to 4 according to the standardized criteria described by Billingham and colleagues ${ }^{30}$ in 1990.

\section{Immunologic assays}

Studies of immune reactivity in vivo to allogeneic targets after xenotransplantation. Recipients were studied for the presence of humoral and cell-mediated reactivity to specific and unrelated allogeneic donors before and after exposure to the xenograft in vivo. Sera were obtained from each recipient for immunologic assays before xenotransplantation and then twice weekly until allograft explantation.

COMPLEMENT-MEDIATED LYMPHOCYTOTOXICITY. Complement binding antilymphocyte antibodies in recipient sera directed against $\mathrm{T}$ and $\mathrm{B}$ lymphocytes of the specific allograft donor and a panel of unrelated baboon donors $(n=12)$ were detected by the standard microlymphocytotoxicity technique. Rabbit complement was absorbed on donor lymphocytes before the cells were added to recipient sera. All testings were done in parallel on purified $\mathrm{T}$ - and B-lymphocyte suspensions to detect antibodies directed against major histocompatibility complex (MHC) class I and class II antigens. Sera were tested before and after reduction of $\operatorname{IgM}$ with dithiothreitol to discriminate between IgM and $\operatorname{IgG}$ lymphocytotoxic antibodies. ${ }^{31}$

Proliferative STUdies. To analyze the potential alloreactivity of recipient $T$ cells infiltrating the xenograft, we explanted graft biopsy specimens in medium supplemented with recombinant interleukin-2 (5 units/ml), and irradiated autologous peripheral blood mononuclear cells. T-cell lines were propagated for 10 to 14 days. Recipient T-cell lines derived from the biopsy specimens were then cultured with irradiated lymphocytes from the xenogeneic and allogeneic donors for 3 days. Over the last 18 hours of culture, the cells were incubated with thymidine labeled with tritium $\left({ }^{3} \mathrm{H}-\mathrm{TdR}\right)(1 \mu \mathrm{Ci} / \mathrm{ml})$. Cultures were harvested and the amount of ${ }^{3} \mathrm{H}$-TdR incorporation was measured in an LK Betaplate liquid scintillation counter (Wallac, Inc., Gaithersburg, Md.).
CyTotoxicity ASSAYS. To determine whether the population of $T$ cells infiltrating the xenograft was composed of xenoreactive and alloreactive cytotoxic $\mathrm{T}$ lymphocytes, T-cell lines derived from the xenograft biopsy tissue were tested for specific cytotoxicity against xenogeneic and allogeneic targets. Lymphocytes $\left(10^{6} / \mathrm{ml}\right)$ from the specific xenograft and allograft donor were stimulated with $2 \mu \mathrm{g}$ phytohemagglutinin (Sigma Chemical Co., St. Louis, Mo.) for 3 days in culture medium (RPMI 1640 medium [Roswell Park Memorial Institute, Buffalo, N.Y.] with $10 \%$ fetal calf serum, glutamine, and gentamicin). The lymphocytes were then collected, washed in culture medium, and labeled at $37^{\circ} \mathrm{C}$ for 1 hour with ${ }^{51} \mathrm{Cr}(0.1$ $\mathrm{mCi} / \mathrm{ml}$ ) for use as targets.

Target cells $\left(10^{4}\right)$ were plated in $96 \mathrm{u}$-bottom plates in a total volume of $0.1 \mathrm{ml}$. Effector $\mathrm{T}$ cells were plated at $5 \times 10^{4} /$ well in $0.1 \mathrm{ml}$ medium. After 4 hours the plates were centrifuged and $0.1 \mathrm{ml}$ supernatant from each well was collected for measuring ${ }^{51} \mathrm{Cr}$ release in a gamma counter (United Technologies Packard, Downers Grove, Ill.). For determination of spontaneous and maximum release, $0.1 \mathrm{ml}$ medium or $0.2 \%$ Triton 100 (Union Carbide Corp., Danbury, Conn.) was added to target cells. Specific lysis was determined by the formula: $100 \times$ (Experimental-spontaneous release/Maximum-spontaneous release).

Studies of immune reactivity to allogeneic targets after priming with xenogeneic cells in vitro. To determine whether $\mathrm{T}$ cells primed by MHC class II-like antigens expressed on xenogeneic donor cells displayed accelerated memory responses against allogeneic targets, we performed the following experiments: Recipient T cells $\left(10^{7} /\right.$ $\mathrm{ml}$ ), obtained before xenotransplantation, were cultured for 10 days with irradiated splenocytes $\left(10^{7} / \mathrm{ml}\right)$ from the xenograft donor. At the end of the incubation period, lymphocytes were harvested, washed, and plated at $5 \times$ $10^{4}$ /well in 96-well plates. Triplicate cultures were stimulated with an equal number of irradiated lymphocytes from the specific allograft donor and from an additional 11 unrelated baboons. After 2 days of incubation the cultures were labeled with ${ }^{3} \mathrm{H}$-TdR, then harvested 24 hours later, and the amount of ${ }^{3} \mathrm{H}-\mathrm{TdR}$ incorporation was measured.

\section{Results}

Histopathology. The extent and severity of allograft rejection in the baboons was unrelated to the extent and severity of xenograft rejection. The allograft in recipient 1 was explanted at 44 days for reasons unrelated to graft function and the remaining allografts were explanted 8 weeks after transplantation. At the time of explantation, all four allografts were beating. Despite the individual variability of prior histologic xenograft rejection, ranging from mild to severe, all four allografts had a similar degree of potentially reversible histologic rejection (low moderate) (Fig. 1). In all cases, allograft rejection was characterized by multifocal 

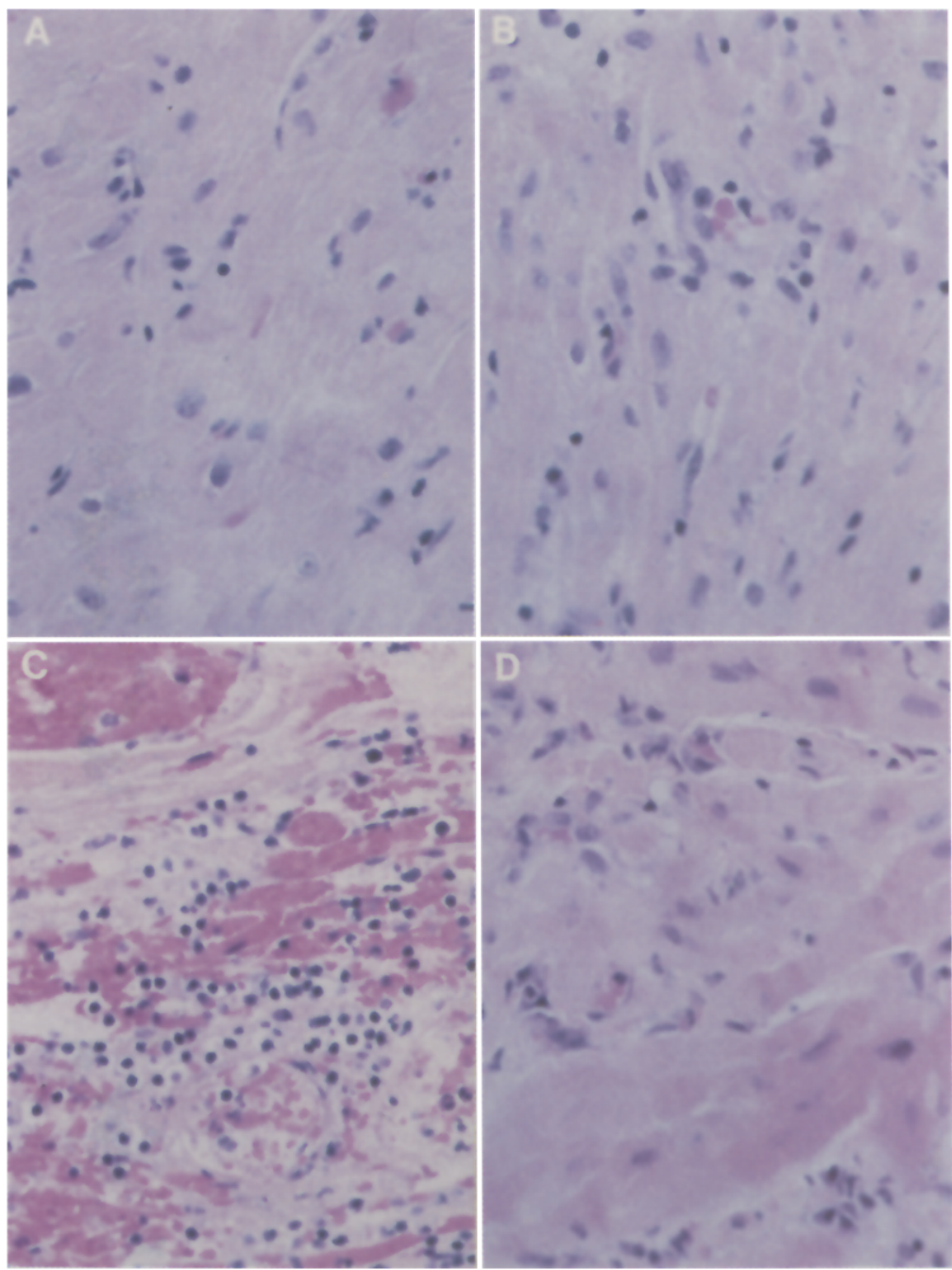

Fig. 1. Light microscopic studies of the xenografts and allografts of recipients 2 and 4 at the time of explantation demonstrating a similar degree of potentially reversible allograft rejection despite variability of prior xenograft rejection (hematoxylin and eosin stain; original magnification $\times 250$ ). A, Xenograft of recipient 2 with no evidence of rejection (grade 1A). B, Allograft of recipient 2 with low moderate rejection (grade $3 \mathrm{~A}$ ) as evidenced by focal areas of cellular infiltrates with some myocyte damage. C, Xenograft of recipient 4 with severe rejection as evidenced by myocyte necrosis, mononuclear cell infiltrates, and intravascular thrombosis. D, Allograft of recipient 4 with low moderate rejection (grade $3 \mathrm{~A}$ ) as evidenced by focal areas of cellular infiltrates with some myocyte damage.

Table I. Proliferative response of primed recipient baboon lymphocytes to stimulating cells of the specific allograft donor and a panel of 11 unrelated baboons

\begin{tabular}{|c|c|c|c|c|c|c|c|c|c|c|c|c|c|}
\hline \multirow[b]{2}{*}{ Baboon } & \multirow[b]{2}{*}{ Cyno donor } & \multicolumn{12}{|c|}{ Stimulator cells-baboon panel } \\
\hline & & $A$ & $B$ & $C$ & $D$ & $E$ & $F$ & $G$ & $H$ & $I$ & $J$ & $K$ & $L$ \\
\hline 1 & $\mathrm{a}$ & - & - & $\rightarrow$ & - & - & - & + & + & - & - & - & - \\
\hline 2 & $b$ & + & - & + & - & - & - & - & - & - & - & - & - \\
\hline 3 & $\mathrm{c}$ & - & -- & - & - & - & + & - & - & - & - & - & + \\
\hline 4 & $\mathrm{~d}$ & - & - & - & - & - & - & + & + & - & - & - & - \\
\hline
\end{tabular}

Baboon $\mathrm{L}$ served as the allograft donor to recipient 1 , baboon $\mathrm{G}$ was the donor to recipient 2 , baboon $\mathrm{I}$ to recipient 3 , and baboon $\mathrm{H}$ to recipient 4 . 

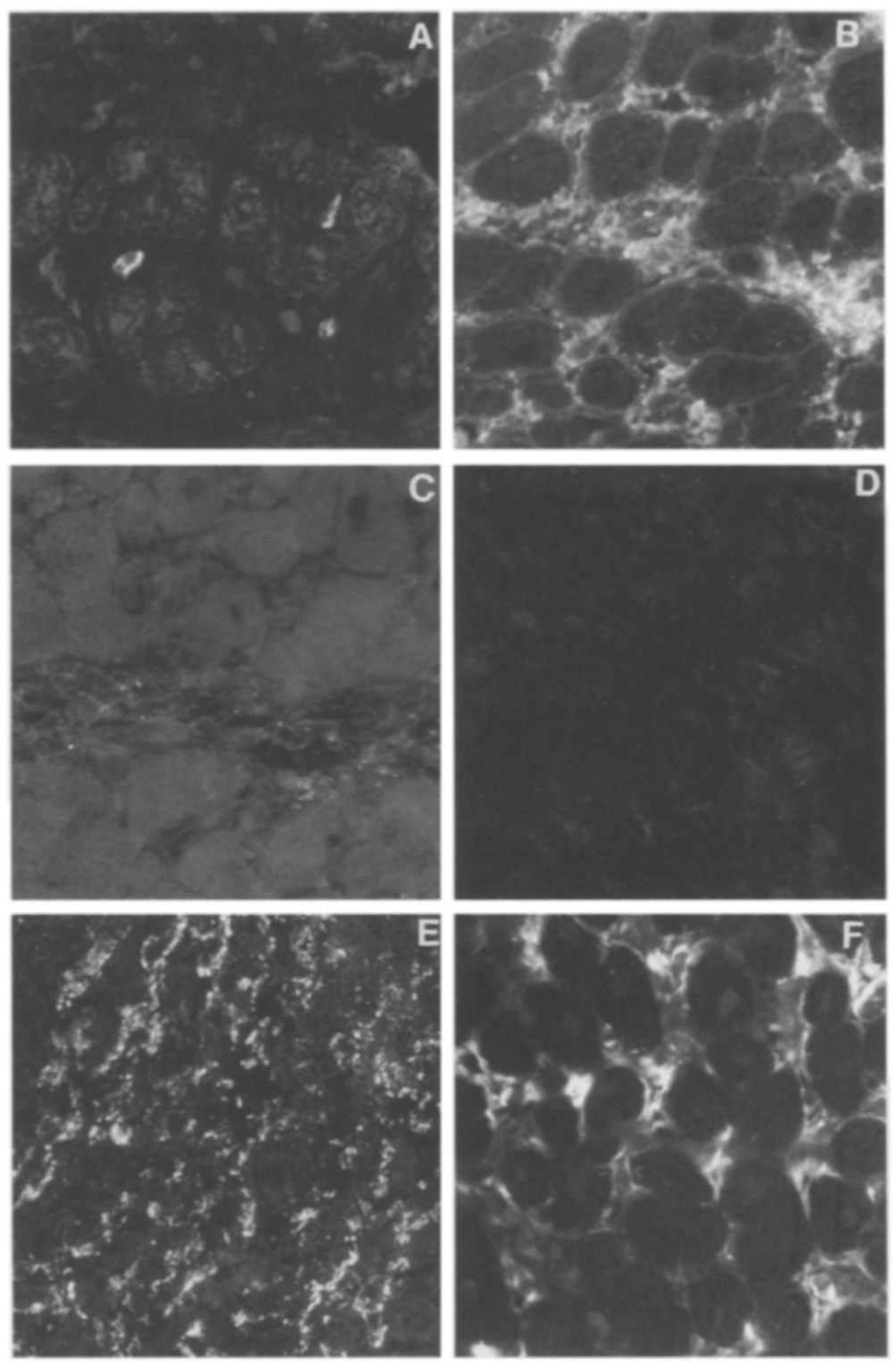

Fig. 2. Immunopathology of a characteristic allograft (recipient 4 ) at the time of graft explantation (8 weeks). A, IgM: Tissue sections reveal focal reactivity at a trace level. B, IgG: Tissue sections reveal trace reactivity in the interstitial space. $\mathbf{C}, \mathrm{C} 3$ : Tissue sections reveal no significant reactivity. D, C4: Tissue sections reveal no significant reactivity. E, MAC: Focal reactivity is apparent in the interstitium. F, Fibrin: Focal fibrin thrombi are present in small vessels and in the interstitium.

cellular infiltrates with some myocyte damage. Immunofluorescence revealed no significant endothelial cell deposition of IgM, IgG, C3, C4, or membrane attack complex at any time points after allotransplantation (Fig. 2).

Humoral response. Before xenotransplantation, two of the four baboons (recipients 2 and 3) had preformed alloreactive antibodies against MHC class II-like antigens of six and seven baboons in the panel $(n=12)$, respectively. After xenotransplantation, no additional alloreactive antibodies developed in either of these baboons. During the time interval from xenotransplantation to allotransplantation both recipients 1 and 4 acquired new-onset alloreactive cytotoxic antibodies directed against the MHC class II-like antigens of six of the 12 members in the panel. These were primarily of IgG isotype. In baboon recipient 1 , the subsequent allograft donor 
was among the baboons against which alloreactive antibodies developed after xenotransplantation. However, this did not have any obvious bearing on the severity of histologic allograft rejection, inasmuch as grade $3 \mathrm{~A}$ rejection at explantation was found in this as well as all other allografts.

After allotransplantation, new-onset alloreactive and xenoreactive antibodies developed simultaneously in one baboon (recipient 2). So that we could establish whether this animal's serum contained two populations of antibodies, one reacting with xenogeneic and the other with allogeneic lymphocytes, or whether there was a single population of antibodies reactive with both species, serum was preadsorbed on either xenogeneic or allogeneic lymphocytes and then tested for reactivity with either target cell type. Antibody reactivity against xenogeneic lymphocytes could be removed by preadsorption of serum on xenogeneic but not allogeneic lymphocytes. Similarly, alloreactive antibodies were removed by preadsorption on allogeneic but not xenogeneic cells. These results indicate that in addition to the induction of specific alloantibodies, allotransplantation after xenotransplantation can reactivate B-cell clones with specificity for xenogeneic antigens.

Cell-mediated proliferative and cytotoxic responses. The $\mathrm{T}$-cell lines propagated from the xenograft biopsy tissue demonstrated no proliferative responses when cultured with xenogeneic or allogeneic irradiated peripheral blood mononuclear cells. The proliferative response of recipient lymphocytes primed in vitro by xenograft donor splenocytes to lymphocytes from the specific allograft donor and a panel $(n=12)$ of unrelated allograft donors was then determined (Table I). After priming with xenogeneic splenocytes, each baboon recipient demonstrated an accelerated proliferative response to two of 12 unrelated baboons in the panel. One of the four baboon recipients (recipient 4) had a proliferative response to its subsequent allograft donor. Recipients 1 and 4 had a proliferative response to the same two baboons in the panel, raising the possibility that these recipients were responding to similar MHC class II-like structures. In the absence of priming, there was no proliferation of recipient lymphocytes to the unrelated baboons in the panel.

To determine whether the T-cell lines infiltrating the xenografts contained donor-specific cytotoxic T lymphocytes, we performed cell-mediated lymphocytotoxicity assays. In three of the four baboons, T-cell lines propagated from xenograft biopsies had

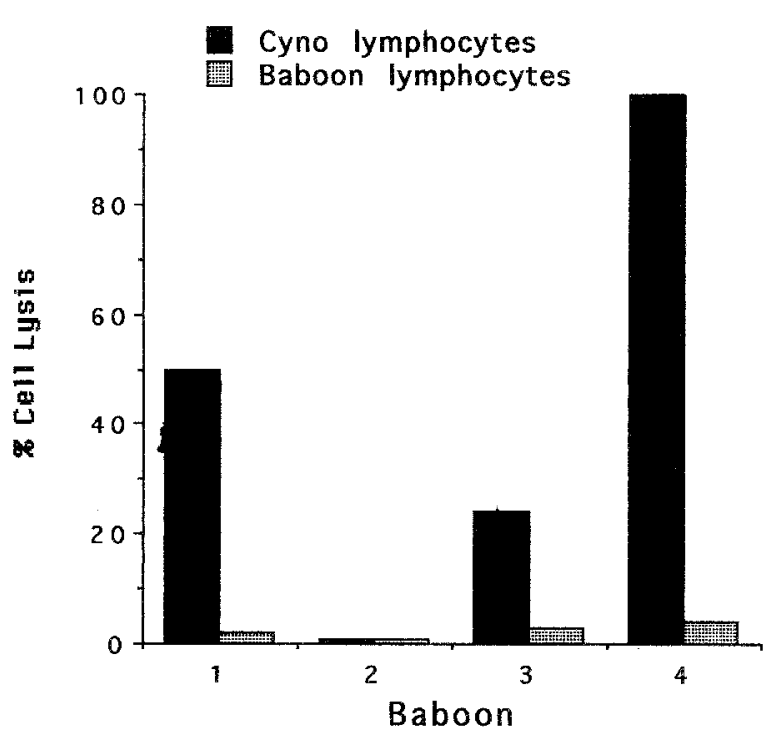

Fig. 3. Cell-mediated lymphocytotoxicity of xenograft Tcell lines to xenogeneic and allogeneic target cells.

specific cytotoxic activity to xenogeneic target cells (Fig. 3). In contrast, none of these lines had cytotoxic activity directed against the subsequent allograft donor.

\section{Discussion}

This study demonstrates that a concordant primate xenograft bridge does not induce an accelerated humoral or cell-mediated immune response that jeopardizes a subsequent allograft. Moreover, the degree of xenospecific immune reactivity, as determined by specific cytotoxicity of recipient $T$ cell lines derived from the xenograft, and extent of histologic xenograft rejection did not predict the extent or severity of subsequent allograft rejection. In two of the four recipients, xenotransplantation induced an alloreactive humoral response against the MHC class II-like antigens of more than $50 \%$ of members from a panel of 12 unrelated baboons. In all recipients, priming with xenogeneic splenocytes in vitro induced an accelerated proliferative $\mathrm{T}$-cell response to allogeneic lymphocytes from $16 \%$ of this panel. However, the induction of allospecific antibody and T-cell proliferative responses by xenotransplantation did not appear to adversely inffuence allograft function inasmuch as the histologic appearance of all allografts at explantation was similar, irrespective of whether alloreactive responses, including those directed to the specific allograft donor, had been present before allotransplantation. 
CD4 $\mathrm{T}$ lymphocytes play a major role in the initiation of both humoral and cell-mediated alloreactive immunologic responses in clinical transplantation. These immunologic responses primarily develop as a consequence of CD4 T-cell allorecognition of foreign $\mathrm{MHC}$ class II antigens. In our model, baboon memory CD4 $\mathrm{T}$ cells reactive with xenogeneic MHC class II-like antigens are likely to have persisted even after xenograft explantation. Inasmuch as prior exposure of baboon CD4 $\mathrm{T}$ cells to xenogeneic targets induced accelerated humoral and $\mathrm{T}$-cell proliferative responses against unrelated allogeneic targets, it is likely that the baboon memory CD4 $\mathrm{T}$ cells recognized similar MHC class II structures present in the xenografts and in the allogeneic cells. Although allotransplantation in the setting of preformed donor-specific antibodies and T-cell proliferative responses did not adversely influence outcome in this model, the presence of similar alloresponses after xenotransplantation in human beings could theoretically preclude the use of donors against which recipients have acquired humoral sensitization. It is important to note that the baboon recipients in this study received immunosuppression with a regimen containing azathioprine. Current strategies to limit the development of humoral immunity after xenotransplantation would include substitution of mycophenolic acid or other newer agents with more potent anti-B-cell activity.

Whether limited proliferative responses to allogeneic targets would also be induced in human beings by xenotransplantation, and whether these would have a significant impact on allograft survival, requires investigation. Although performance of a mixed lymphocyte reactivity test between a concordant xenograft recipient and any potential allograft donor appears indicated, time considerations would make it difficult to perform a 24- to 48-hour proliferative assay after a potential allograft donor has been identified. However, inasmuch as allorecognition appears directed toward MHC class II antigens, one could perform prospectively primed mixed lymphocyte reactions to cell panels of known human leukocyte antigen class II (DR/DQ) type and identify which antigens elicit a proliferative response. Human leukocyte antigen class II typing could then be performed on potential donors to exclude those with the antigens known to elicit a proliferative response.

This study demonstrated that concordant xenografts implanted in primates as a bridge to allotransplantation did not induce humoral or cell- mediated immune responses that jeopardized subsequent allografts. However, our findings do suggest that concordant xenotransplantation may induce cross-reactive allorecognition of MHC class II-like structures. While affirming the role of concordant xenografts as appropriate biologic bridges to human allotransplantation, the immune responses resulting from the potential sensitization by a xenograft may affect the process of subsequent allograft donor selection.

\section{REFERENCES}

1. Evans RW, Orians CE, Ascher NL. The potential supply of organ donors: an assessment of the efficiency of organ procurement efforts in the United States. JAMA 1992;267: 239-46.

2. Oriens CE, Evans RW, Ascher NL. Estimate of organspecific donor availability for the United States. Transplant Proc 1993;25:1541-2.

3. 1994 Annual Report of the US Scientific Registry of Transplant Recipients and the Organ Procurement and Transplantation Network. Richmond (VA): UNOS.

4. $\mathrm{Oz} \mathrm{MC}$, Goldstein DJ, Pepino P, et al. Screening scale predicts patients successfully receiving long-term implantable left ventricular assist devices. Circulation. In press.

5. Reemtsma K, McCracken BH, Schlegel JU, et al. Renal heterotransplantation in man. Ann Surg 1964;160:384-410.

6. Hardy JD, Kurrus FE, Chavez CM, et al. Heart transplantation in man: developmental studies and a review of a case. JAMA 1964;188:1132.

7. Barnard CN, Wolpowitz A, Losman JG. Heterotopic cardiac transplantation with a xenograft for assistance of the left heart in cardiogenic shock after cardiopulmonary bypass. S Afr Med J 1977;52:1035.

8. Bailey LL, Nehlsen-Cannarella SL, Concepcion W, Jolley WB. Baboon-to-human cardiac xenotransplantation in a neonate. JAMA 1985;254:3321-9.

9. Michler RE, McManus RP, Smith CR, Sadeghi AN, Marboe $\mathrm{CC}$, Reemtsma $\mathrm{K}$, et al. Prolongation of primate cardiac xenograft survival with cyclosporine. Transplantation 1987; 44:632-6.

10. McManus RP, Kinney T, Komorowski R, Hunter J. Reversibility of cardiac xenograft rejection in primates. J Heart Lung Transplant 1991;10:567-76.

11. Kawauchi M, Gundry SR, de Bogona JA, Razzouk AJ, Bouchart F, Fukushima N, et al. Prolonged survival of orthotopically transplanted xenograft in infant baboons. J Thorac Cardiovasc Surg 1993;106:779-86.

12. O'Hair DP, McManus RP, Komorowski R. Inhibition of chronic vascular rejection in primate cardiac xenografts using Mycophenolate Mofetil. Ann Thorac Surg 1994;58: 1311-5.

13. Calne RY. Organ transplantation between widely disparate species. Transplant Proc 1970;2:550-3.

14. O'Hair DP, McManus CP, Johnson CP, Scott JP. The role of antiendothelial cell antibody in primate cardiac xenograft rejection. Transplant Proc 1992;24:506-7.

15. Kurlansky PA, Sadeghi AM, Michler RE, Smith CR, Marboe 
CC, Thomas WA, et al. Comparable survival of intra-species and cross-species primate cardiac transplants. Transplant Proc 1987;19:1067-71.

16. Roslin MS, Tranbaugh RE, Panza A, Coons MS, Kim YD, Chang $\mathrm{T}$, et al. One-year monkey heart xenograft survival in cyclosporine-treated baboons. Transplantation 1992;54:949-55.

17. Rosengard BR, Adachi H, Ueda K, Hall TS, Hutchins GM, Herskowitz A, et al. Differences in the pathogenesis of first-set allograft rejection and acute xenograft rejection as determined by sequential morphologic analysis. J Heart Transplant 1986;5:263-6.

18. Matsumiya G, Shirakura R, Miyagawa S, Izutani H, Sawa $Y$, Nakata $S$, et al. Analysis of rejection mechanism in the rat to mouse cardiac xenotransplantation. Transplantation 1994;57: $1653-60$.

19. Steinbruchel DA, Nielson B, Salomon S, Kemp E. Sequential, morphologic, and anti-donor antibody analysis in a hamster-to-rat heart transplantation model. Transplant Int 1992;5:38-42.

20. Di Stefano R, Carobbi A, Frosini F. Secondary allogeneic challenge of xenotransplant recipients. Transplant Proc 1992; 24:694-5.

21. Gannedahl G, Tufveson G. The impact of xenograft rejection of future grafting. Transplant Proc 1992;24:276-8.

22. Hammer C, Schütz A, Pratschke J, Breuer M, Engelhardt M, Brandl $\mathrm{U}$, et al. Bridging to transplant: allogeneic heart transplantation after xenografting. J Heart Lung Transplant 1992;11:S182-8.

23. Alonso de Bogona J, Gundry S, Kawauchi M, Bailey L, Gusewitch G, Fagoaga O, et al. Assessment of baboon lymphocyte subsets and activity in cardiac xenobridging to allotransplantation. Transplant Proc 1992;24:453-4.

24. Michler RE, Socha WW, Marboe CC. Macaque-to-baboon cardiac transplantation: model of choice for xenotransplantation in humans. Transplant Proc 1988;20(S1):327-8.

25. Socha WW, Marboe CC, Michler RE, Rose EA, MoorJankowski J. Primate animal model for the study of ABO incompatibility in organ transplantation. Transplant Proc 1987;19:4448-55.

26. Michler RE, Marboe CC, Socha WW, Moor-Jankowski J, Reemtsma K, Rose EA. Simian-type blood group antigens in non-human primate cardiac xenotransplantation. Transplant Proc 1987;19:4456-62.

27. Michler RE, McManus RP, Smith CR, Sadeghi AN, Rose EA. Technique for primate heterotopic cardiac xenotransplantation. J Med Primatol 1985;14:357-62.

28. Platt JL, Fischel RJ, Matas AJ, Reif SA, Bolman RM, Bach $\mathrm{FH}$. Immunopathology of hyperacute xenograft rejection in a swine-to-primate model. Transplantation 1991;52:214-20.

29. Platt JL, Michael AF. Retardation of fading and enhancement of intensity of immunofluorescence by p-phenylenediamine. J Histochem Cytochem 1983;31:840.

30. Billingham ME, Cary NRB, Hammond ME, Kemnitz $J$, Marboe C, McCallister HA, et al. A working formulation for the standardization of nomenclature in the diagnosis of heart and lung rejection: heart rejection study group. J Heart Transplant 1990;9:587-601.

31. Pirofsky B, Rosner ER. DTT test: a new method to differentiate $\operatorname{IgM}$ and $\operatorname{Ig} G$ erythrocyte antibodies. Vox Sang 1974; $27: 480$. 